\title{
An Examination of Social Adaptation Processes of Vietnamese Adolescents
}

\author{
Fayneese Miller, My Do and Jason Sperber ${ }^{1}$ \\ Brown University
}

The purpose of the study was to examine the factors that affect the ways in which Vietnamese youth feel about themselves and their "place" in society. More specifically, the purpose was to determine the relationship between sociocultural factors (i.e. language proficiency, length of residence, socioeconomic class, ethnic identity, and cultural continuity) and such person-oriented variables as depression and alienation. Thrity-one college and fifteen high school students responded to a series of questions about themselves, family, relationships, personality, and achievement motivation. It was found that perceived problems with one's ethnic group, cultural continuity, and parental attitudes toward schooling significantly predicted depression. Degree of attachment to one's ethnic community, English speaking and writing abilities, and outlets for derpession tended to predict future outlook or feelings of hope versus alienation. Several variables were highly predictive of acculturation. Some of those variables are native language ability, English speaking and writing ability, outlets for depression, and perceived problems with one's ethnic group. Implications of the findings for Vietnamese youth and future directions are discussed.

Research on children of Asian American children has typically focused on academic achievement. Although such research is of critical importance in the development of cognitive models for achievement, it fails to acknowledge such critical development issues as affective and behavioral development. In fact it has been suggested that Asian American children lag behind other children in social development. The problem with this assertion is that it does not address differences between first, second, and third generation children of Asian descent. Another problem with research on children of Asian descent is that the data is usually aggregated across the various Asian groups. There is a need to 
examine the various Asian groups, especially those of Southeast Asian versus East Asian descent, separately from other groups. The reasons for immigration vary across class. Some have immigrated for economic reasons while others have immigrated purely for political reasons.

Adolescence is a time when young people begin to expand their frame of reference to include peers. Family is no longer the only purveyor of information about the world. In other words, the inclusion of peer perspectives makes for a more socially complex view of the world and contributes to the continuing development of a young person's sense of identity. Research on Asian Americans suggest an authoritarian approach to parenting ${ }^{2}$ and a belief in family as the primary reference point regardless of age of the child. This view of development for Asian families is cultural and generationally limited. In other words, children of Asian descent who are born in the United States and those who immigrated at a very early age are not only Asian but American as well. They experience a double consciousness ${ }^{3}$ or a bicultural identity. This double consciousness often conflicts with the values of the family. For example, the "parenting" culture might dictate that young people enter into an arranged marriage, often when the female is still of high school age. The young female who is second generation or immigrated during early childhood and who is bicultural might object to such an arrangement. The young female who is a recent immigrant and primarily monocultural in upbringing and experiences might be less likely to object. The first female has internalized the values of her peer group as well as those of her parents. Her identity is a product of a socially complex interaction of experiences.

This study focuses on the social and cultural development of Vietnamese first versus second and third generation adolescents. One purpose of the study is to examine the degree of acculturation or social adaptation as a result of language, length of residence, and ethnic group identity. A second purpose is to determine whether or not perceptions about and expectations associated with one's ethnic identity affect a person's perception of their "place" within family or other social entities.

\section{Background and Overview}

Vietnamese, especially those who are first generation, are often categorized as refugees. A refugee is defined as any individual who leaves his or her country of birth because of fear of persecution due to race, religion, nationality, or membership in a particular social group. Refugees are usually unable to take advantage of safety and protection mechanisms that exist within their country of birth and are often unwilling or unable to return. Kunz describes two types of refugees--the acute and the anticipatory refugee. ${ }^{4}$ The acute refugee is someone who leaves his or her country of birth due to political change or military actions. The 
acute refugee has little or no grasp of his or her adopted country's language or cultural mores. They therefore are likely to experience cultural incompatibility, alienation, and family turmoil. This view of first generation immigrants is one that minimizes educational background and social adaptability. It also does not address age differences. While the negative experiences might be true for late adolescents and adults, young children, who have not yet entered middle childhood, might experience fewer negative cultural effects and greater social adaptability with the adopted country since middle childhood is when reference points begin to shift from parents to peers. The anticipatory refugee or immigrant, on the other hand, is someone who leaves his or her country before military actions or political destabilization prohibit an orderly departure. Anticipatory refugees are often prepared for resettlement in another country. They are familiar with the language of their adopted country and have some means of financial support or some idea about how they might support themselves or reenter their profession upon immigration. Again, this view does not address the needs of young people but does address the fact that cultural incompatibility is not always a factor for immigrants to the United States. Middle to late adolescents who have the general appearance of an anticipatory refugee but none of the financial concerns are also likely to have fewer adaptation or compatibility issues.

Vietnamese began the immigration process during the fall of 1975. The early immigrants are technically referred to as acute refugees. It is somewhat difficult to classify those who arrived during the 1980s since some had some command of the language but few visible means of financial support. The first wave of immigrants from Vietnam was somewhat educated but lacked kinship networks or ethnic supports in the United States. They were also distinct both culturally and ethnically from people in the United States. The lack of kinship networks and established Vietnamese communities encouraged the need to learn English and American culture. The absence of an established community and the need to learn how to negotiate one's way within an adopted country could lead to feelings of alienation toward one's culture of origin and greater assimilation among young people.

The second wave of immigrants was less likely to experience the need to assimilate or experience alienation because of established ethnic supports, communities, and social welfare structures. ${ }^{5}$ The need to "learn the culture" could be less urgent, especially for adults. In order to survive, the first wave had a need to learn the culture, thereby successfully enhancing their ability to negotiate, integrate, and achieve upward mobility within their "new" country. Jones and Strand have shown that contact with people outside of one's ethnic group or community is essential for "successful" adaptation to another way of life. ${ }^{6}$ The lower the degree of outside community contact, the more difficult it is to adapt to another way of life. It is therefore argued in this study that second 
generation Vietnamese adolescents will be more socially adapted than recent immigrants but will also experience greater cultural discontinuity with their own ethnic culture and family than later immigrants.

\section{Psychological Well-Being and Social Supports}

As stated previously, the first wave of immigrants provided ethnic and social support for the later wave of immigrants. Given the fact that social supports are readily available for later immigrants, the later group would have a less urgent need to learn the "new" culture. They are also less likely to experience cultural discontinuity. In fact, some researchers ${ }^{7}$ have found that ethnic social and tangible support from family and friends can affect one's feelings of well-being and decrease alienation. The more functional and meaningful the social supports, the higher the individual's sense of well being.

The more supportive one's social networks and the longer the time of residence in the United States, the less one is likely to feel alienated. ${ }^{8}$ On the other hand, the higher one's personal level of anxiety, the greater the degree of expressed alienation. Specifically, young people who have very practical reasons for needing to learn a new culture must negotiate two very different worlds--the world of the ethnic enclave in which they live and the world outside that enclave. The process of negotiating between the two "worlds" could lead to ethnic identity issues and increased anxiety about one's cultural group. For these young people the enclave provides the supports necessary to decrease anxiety on one hand but increase it on the other. The pressure to participate in ethnic related celebrations and events at the same time the young person is adjusting to or acquiring another identity could lead to a great deal of anxiety for young children. It would seem, tinerefore, that length of residence in the United States is a major variable in the development of feelings of alienation and anxiety.

Although an orthogonal relationship has been found between length of residence and alienation, ${ }^{9}$ the opposite also has been found. The longer the length of residence the more alienation. It is suggested that the more bicultural the individual, the greater the degree of normlessness, isolation, and powerlessness, all components of alienation. Biculturality may lead to heightened intergroup or interethnic conflict. It can also lead to increased conflict with parents. Asian American youth, as they become more socialized by American values and begin to behave according to prescribed American norms rather than Asian norms, often have difficulty with parents and members of their ethnic enclave when attempting to act on or out those "new" American values. The traditional values of the home conflict with those of the larger society. Several researchers have found that intergeneration differences ${ }^{10}$ and the degree of adaptation anc acculturation to mainstream culture 
often result in parent-child relational conflicts. ${ }^{11}$ This is complicated by the fact that the bicultural youth, because of their language abilities and knowledge of the "new" culture, often assume many of the roles that parents are usually responsible for, like negotiating with bank officers, grocery personnel, and bill collectors. They become the family spokesperson. ${ }^{12}$ So, on the one hand the young person is encouraged to learn the new culture, while on the other they are criticized for becoming a part of that culture. It is argued in this paper that this situation has negative consequences for the psyche of Asian American youth.

Several researchers ${ }^{13}$ have proposed that the ability to understand and communicate in the host country's language is a major predictor of economic and social success. Roberts and Starr, ${ }^{14}$ for example, have found that a refugee's command of the English language is an important factor for smooth transitions and biculturality. In other words, the greater the language proficiency, the greater the cultural, structural, and marital assimilation.

\section{Ethnic Identity Development}

Learning to cope during adolescence while at the same time experiencing cultural discontinuity within another country adds to the stress that young people often experience during adolescence. Matsuoka states that the age at which a young person comes to United States is a significant determinant of how quickly the person learns and adapts to American behavorial patterns. ${ }^{15}$ Vietnamese adolescents, for example, arrive in the United States at a critical and vulnerable time during their identity development. The adolescents, since they have no well-formed cultural or personal identities, are easily influenced and confused by the juxtaposition of Vietnamese versus American values in their life. More specifically, while the family sees traditional values and the family's interest as taking precedence over the wants, needs, and desires of individual family members, young people are trying to carve out a separate indentity from the family.

The need to achieve a separate, yet attached identity is a normal part of development. Unfortunately for the young immigrant, the culture in which one is attempting to develop a separate identity is different from that of the home. While the non-native culture encourages independent thinking and decision-making, the native culture encourages subjugation of self for the good of the family.

Traditional values and expectations are challenged by the norms, values, and survival needs experienced in the host country. Southeast Asian girls, who are expected to assume a traditional role and place within the structure of the family, often are forced to work outside the home to ensure basic survival of the family. The changed role and expectations for some Southeast Asian girls creates conflict and threatens 
to disrupt or lead to the breakdown of traditional patterns of familial and cultural behavior. ${ }^{16}$ The adolescents are often forced to leave school to marry or work in order for the family to survive.

Although traditional patterns of behaving are often threatened by the realities that one must confront in the adopted country, the prioritization of traditional values and beliefs are not totally disbanded. To exemplify this phenomenon, Nguyen and Williams surveyed Vietnamese and White adolescents and their parents about Vietnamese and American values. ${ }^{17}$ They found that regardless of the time spent in the United States, Vietnamese parents still strongly endorsed traditional family values while Vietnamese adolescents tended to reject those values. This generation gap was greater for girls than for boys. These changing gender roles may further point to the intergenerational conflict that arises when ethnic youth become bicultural.

Interestingly, it has been found that Vietnamese parents approve of certain adolescent privileges like freedom of choice regarding dating, marriage, and career but encourage absolute obedience to parental authority. This could create a cultural conflict for the adolescent and further affect intergenerational relations. ${ }^{18}$ The message that parents convey is "become a success in the United States, but find a way to do it without becoming American; be grateful for your freedom here, but don't embrace it as a way of life." The adolescent, who experiences this mixed message, must contend simultaneously with the development crisis associated with the formation of identity and the biological crisis of "coerced homelessness." Adolescents who are continuously pressured to choose one culture over another could become depressed.

\section{Factors Which Contribute to Depression}

Several factors have correlated with the development of depression among Southeast Asians. Callies et al., in a study of depression and alienation, found that depression symptoms remained high for those Hmongs who were socially isolated (alienated), unemployed, and nonEnglish speaking. ${ }^{19}$ Nguyen and Peterson, on the other hand, observed that acculturation to American society was positively correlated with increased reports of depressive symptoms and the occurrence of stressful life events for Vietnamese-American college students. ${ }^{20}$ This was especially so for young females who had a lessened identification with Vietnamese society.

Nguyen and Peterson posit that a lack of identification with a single culture leads to depression. ${ }^{21}$ Feelings of being more American and less Vietnamese may result in an identity crisis and lead to depression and stress. These feelings are heightened when relations between the parent and child or among peers are strained. Given the competing roles of Southeast Asian girls, it is not surprising that females experience more depression than males. ${ }^{22}$ 


\section{Education and Acculturation}

Level of education has been proposed as a predictor of ethnic group members' attitudes toward the United States. Henkin and Nguyen, and Forward and Rick proposed that the longer one has been in the United States and the higher the level of education, the less positive the attitude toward the United States. ${ }^{23}$ In another study Celano and Tyler found that education was predictive of acculturaion or the learning process through which at least some of the cultural patterns of the host country are adopted. ${ }^{24}$ Although education determines socioeconomic status, Celano and Tyler have found that education alone is less predictive of acculturation than socioeconomic class. ${ }^{25}$ Given that education refugees often work at jobs for which they are overqualified, education becomes less of a factor for acculturation than socioeconomic class. The higher the class level the greater the social mobility.

In sum, the personality and social development of Vietnamese adolescents is influenced by such factors as age at immigration, education level of parents, exposure and attachment to like-ethnic group community, and immigration status. The study reported in this paper is an attempt to further understand the psychological development of Vietnamese adolescents.

\section{METHODS}

Subjects: The Southeast Asians who participated in this study were Vietnamese, Laotian, and Hmong. The Hmong and Laotian samples were too small to allow for reliable statistical analysis; therefore, only the Vietnamese data is reported in this paper. A total of 46 Vietnamese young people, 31 college and 15 high school students in the northeast, responded to a series of items included in a survey packet. Table 1 provides background information on the participants. Of the 31 college students, 12 were male and 19 were female. Also, none of the college students were recent immigrants or acute refugees. Of the high school students, seven were male and eight were female. All of the high school students were relatively recent immigrants. The mean age for the college students was 20.2 with a range of 18 of 23 and the mean age for the high school students was 17.6 with an age range of 14 to 21 .

Materials and Procedure: A survery packet was mailed to all students at a northeastern university who were listed as Vietnamese. Thirty-five students were identified through this process. The return rate of the mailed surveys for this group was $88.5 \%(\mathrm{~N}=31)$. High school students who were enrolled at a particular school in the northeast and were listed as Vietnamese were also mailed survey packets. The return rate for this group was $95 \%(\mathrm{~N}=15)$. In order to assure the reliability of items for the high school students, the items in the survey packet were 
translated into Vietnamese by a trained translator and later retranslated back into English for analyses.

Items included in the survey packet were based on the work of various researchers. ${ }^{26}$ Celano and Tyler measured the extent to which an immigrant adopted American habits, life style, language, and customs by using Szapocznik's Behavorial Acculturation Scale (BAS). ${ }^{27}$ The alpha coefficient for the BAS is .72. Seven of the 24 BAS items were used in this study. The items focused on language spoken at home, work, school, and with friends. The items also focused on the language listened to on radio and read. The Cronbach alpha for the revised scale items was .53.

Nguyen and Peterson, to measure degree of identification, have used seventeen questionnaire items with Vietnamese regarding acculturation to America society. ${ }^{28}$ The Cronbach alpha for these items for this sample is .61. In order to assess Vietnamese adolescents and their parents' attitudes toward Vietnamese as compared to Western values, 16 items from a 29 item 5-point likert-type scale were used. The items were labeled relationship factors and dealt with gender roles and parental relations. Some of the relationship items were "the oldest girl in the family should help her parents take care of the house and the younger children whether she wants to or not;" "boys should have more privileges than girls," and "a woman's job is as important as her husbands." Some of the relational items were "youth should not argue with adults; parents always know what is best" and "when family members are angry with each other they should let each other know."

Eleven items from the Jones and Strand study, ${ }^{29}$ which focused on perceived problems confronting Vietnamese in America, were administered. The problems to which the students were asked to respond dealt with money, difficulty in understanding American life, English language problems, ethnic support, etc.

Twenty-three items measuring reference group assimilation were used..$^{30}$ These items refer to the establishment of close intergroup relations and occupational, educational, and other institutional integration. The Cronbach alpha for the revised questionnaire was .79. The items dealt with language fluency, ethnic community proximity, ethnicity of preferred partner, and traditional values.

The depression subscale from Rumbaut's Indochinese health and adaptation research project was used. ${ }^{31}$ The items on the depression subscale ask "how often in the past month have you felt"... and "when I'm depressed I...." The Cronbach alpha for the depression subscale is .80 .

Finally a background information questionnaire was included in the survey packet. The background information items asked about ethnicity, gender, age, year of immigration to the United States, years of schooling in the United States, and educational level of parents. 


\section{RESULTS}

\section{Background Information}

Ninety-two percent $(\mathrm{N}=12)$ of the male and $79 \%(\mathrm{~N}=19)$ of the female college students were born in Vietnam as compared to $100 \%$ $(\mathrm{N}=7)$ of the male and $100 \%(\mathrm{~N}=8)$ of the female high school students. However, the male $(M=14.5, S D)$ and female $(M=12.26, S D=4.05)$ college students had more schooling in the United States than the high school male $(M=2.14, S D=1.07)$ and female $(M=3.38, S D=3.16)$ students. This is explained by the age of arrival in the United States. The college students were more likely to have immigrated to the United States between the ages of 1 to 13 as compared to high school students who tended to have immigrated between the ages of 12 to 20 .

The socioeconomic status of the students varied for the college and high school students. Sixty-seven percent $(N=21)$ of the college students were middle to upper middle class compared to $7 \%(\mathrm{~N}=1)$ of the high school students. Ninety-one percent $(\mathrm{N}=13)$ of the high school students were working to lower class compared to $32 \%(N=10)$ of the college students.

In addition, father's education level was positively correlated with mother's level of education $(r=.68 p<.01)$ and family socioeconomic status $(r=.58 p<.01)$. The higher the level of parents' education the higher the family's socioeconomic status.

\section{Cultural Attachment and Values}

Several regression analyses, controlling for unequal Ns, were conducted. The presence of a Vietnamese ethnic enclave, $F(2,44)=$ $6.39, p<.05)$ and the ability to speak and write English, $F(2,44)=7.96$ $\mathrm{p}<.05)$ significantly predicted feelings of alienation and an increased future outlook. Established kinship networks and a supportive surrounding ethnic community tend to affect one's feelings about his or her future and place within society. The college students tended to have fewer. ethnic contacts or associations and express more alienation than the high school students.

Other multiple regression analyses revealed that perceived problems with one's ethnic group, $F(3,43)=4.94 p<.05$, cultural continuity, $F$ $(3,43)=4.19 p<.05$, and paternal attitudes toward schooling, $F(3,43)=$ $5.55 \mathrm{p}<.05$, predicted depression among Vietnamese adolescents. Cultural continuity in this study involves familiarity with Vietnamese traditions and customs, celebration of Vietnamese holidays, indoctrination of future generations in Vietnamese traditions, beliefs that are in agreement with traditional Vietnamese beliefs and values, adoption of parents' major philosophies about family and tradition, and consideration fo 
parents' feelings when making important decisions. Adolescents who believe in and celebrate Vietnamese customs and traditions, whose beliefs are consistent with their parents and involve parents in all major decisions are less depressed than those who experience cultural discontinuity.

The more seriously one perceives such problems as a lack of money, separation from the family, lack of ethnic support, language comprehension difficulties, poor housing conditions, and interethnic conflict the more he or she expresses feelings of depression. Also, the stronger parents feel about their children getting good grades or working hard in school, the more likely their children are to feel depressed.

Vietnamese adolescents hold traditional beliefs about their culture. The longer the residence in America the higher the acculturation, $F(, 44)=4.42 P<.03$. The presence of an ethnic community also tended to lead to less acculturation, $F(, 44)=4.34 p<.02$. This was especially true for the high school Vietnamese males.

\section{Correlations of Personality and Alienation Variables}

Younger college females were more depressed than older college females $(r=.54)$. In addition preference for the American way of life and preference of untraditional female gender roles were positively correlated $(r=.74)$. On the other hand college female students who prefer traditional female gender roles are more likely to have a positive future outlook $(r=.53)$. The more years of education females have and the more they believe in traditional Vietnamese values, the more likely they are to have a negative future outlook or feel alientated $(r=.50)$. Females who are acculturated tend not to prefer the Vietnamese way of life $(r=.63)$. The more traditional the females, the more they prefer traditional gender roles.

A positive relationship was found between depression and preference for untraditional parental relations $(r=.69)$. College males who preferred untraditional parental relations tended to be depressed, to have a positive future outlook $(r=.66)$., and to identify as Vietnamese $(r=$ .65). College males who prefer traditional parental relations $(r=.88)$ and are more proficient in Vietnamese $(r=.80)$ tend to be less acculturated.

High school females were less likely to feel depressed than college students. Although length of stay per se is not correlated with depression, one could speculate that it does play a role. The college students have spent more time in the United States than the high school student but they are more likely to be depressed. On the other hand, the more traditional high school males are in their beliefs about parents and culture, the more negative their future outlook $(r=.85)$. 


\section{Socioeconomic Class}

The college students tended to have a higher socio-economic class background than the high school students. Sixty-four percent of the college students were middle to upper middle class compared to $7 \%$ for the high school students. In addition, father's level of education was positively correlated with mother's level of education $(r=.68)$ and the combined family socioeconomic class $(r=.58)$. The higher the parents' level of education the higher the family's socioeconomic class.

\section{Self-Identification of the Adolescents}

The majority of the college students identified as VietnameseAmerican, while less than one-fourth of the high school students identified as Vietnamese-American. The high school females were more likely to identify as Vietnamese (75\%), while $43 \%$ of the high school males identified as Vietnamese and the other $43 \%$ were unsure of their identification.

\section{Social Development and Academic Achievement}

The academic achievement of the students is presented in Table 1. All of the students, with the exception of the high school females, were doing well academically. Nearly half of the grades reported by the high school females was "D." The high school females spent more time on homework than the other students but benefited the least. The precarious role of high school females within traditional Vietnamese families may explain their relatively mixed academic performance. On one hand the females are expected to achieve academically, on the other to be subservient to the family and behave according to prescribed traditional beliefs and customs.

The social behavior of the students is not atypical adolescent behavior. Many young people use alcohol and drugs but do not abuse alcohol and drugs.

\section{Parental Involvement in Schooling}

Parents respond differently to the achievement behavior of males versus females. Seventy-five percent of the males stated that their parents get upset when they get bad grades, $25 \%$ of the high school students' parents get upset, and $14 \%$ of the college females and high school males' parent get upset (see Table 2). The response of the parents of the high school females might explain the fact that $43 \%$ get grades of "D." The parents tend not to be satisfied with the performance of the females, no matter how good. 


\section{Depression Among Adolescents}

Overall, college students tend to be more depressed than noncollege aged Vietnamese students. Specifically the collge females $(M=$ $15.37, \mathrm{SD}=3.30$ ) scored lower on a depression scale than college males $(M=17.33, S D=3.00)$, high school males $(M=21.75, S D=3.30)$, and high school females $(M=22.40, S D=1.94)$.

Depression outlets used by the young people are presented in Table 3. College students prefer to spend time alone or talk with friends when they feel depressed. High school students also tended to spend time alone and talk to friends. The high school females, however, tend to talk to parents rather than each other. Having someone to talk to decreases feelings of depression and improves one's views and hopes for the future.

\section{DISCUSSION}

The purpose of the study was to examine factors which lead to feelings of alienation and depression among Southeast Asian adolescents, especially Vietnamese. It was found that perceived problems with one's ethnic group such as cultural discontinuity and parental attitudes toward schooling predicted depression. High school girls were more likely to receive grades of "D" than either high school males or college students. Yet, these females study as often as the others. The girls' parents, however, tend to criticize their academic achievement and to demand better grades no matter how hard they try or how well they do. Coupled with this is the parents' belief that girls should assume a traditional role within Vietnamese families. Given females' need to affiliate, any perception of displease by parents could result in a decreased achievement motivation and self-concept. In addition any perceived cultural discontinuity between the young persons' personal identity and their cultural identity, as defined by parents, could lead to frustration and depression.

English language proficiency was also related to depression. This is contrary to past findings which have shown that those who are least proficient in English have higher rates of depression than those who are more proficient. ${ }^{32}$ In this study, however, students with higher English proficiency and longer lengths of residency were more depressed than those students with less proficiency in English proficiency and relatively short lengths of residency in the United States. It is suggested in this paper that length of residence is related to psychosocial health. Immigrant populations begin to resemble the dominant culture in terms of educational outcomes and mental health issues the longer their residence in the United States. This is regardless of whether or not one has assimilated or become acculturated. Society's perception of ethnic groups affects perception vis-a-vis the dominant culture. 
On the other hand, the greater the students' command of English the more likely they are to have a positive future outlook. Supportive kinship networks or attachment to an ethnic community also influence future outlook. There is a large body of literature in developmental psychology that supports the notion that attachment relations are important for cognitive growth. Specifically, young people who have healthy familial attachments are less likely to be negatively affected by threats to their social and emotional development. . $^{33}$

Several factors predicted acculturation in this study. English language proficiency and use at home versus school, depression outlets, cultural continuity, and parental attitude toward schooling predicted acculturation. The more proficient in English the less the attachment to one's ethnic group, and the longer the stay in the United States the more acculturated the individual. Although it could be argued that length of residence is associated with acculturation, it is probably more reasonable to suggest that the acculturation expressed by longer resident Vietnamese is primarily due to the need to develop a group identity that reflects both their Vietnamese and American culture. Recent immigrants are more likely to be attached to their ethnic group and therefore less likely to be in established Vietnamese communities as compared to the integrated communities of the longer resident Vietnamese. Although the longer resident Vietnamese might live in an integrated community, their parents might still adhere to and practice traditional Vietnamese customs.

The desire of the parents to practice traditional Vietnamese customs may conflict with the adolescents' desire to assimilate, to be like his or her peers. This could lead to young people counterarguing with their parents and an initial embrace of American values. Although this could be viewed as a sign of youthful rebellion, it is also an indication of a search for a personal identity. Miller has proposed that counterarguing is an indication of both an age appropriate level of cognitive development and a temporary alienation. ${ }^{34}$ Specifically, the alienation expressed by the young people in this study is temporary. This is especially true for those young people who were either born in the United States or immigrated at a very early age. The temporary alienation is reflective of a belief in one's inability to affect parents' cultural beliefs, practices, and expectations of their children while still living at home but also a belief that they will gain control over their life after they leave home. Since the young people who tended to express alienation in this study were college age, it seems that the students have a future outlook but an alienation that can best be described as temporary.

Are Vietnamese adolescents who have been in the United States for a significant amount of time ashamed of their heritage or simply trying to reconcile or negotiate between their two very distinct cultural experiences? This question was not addressed in this study. Future research is needed to answer this question. On the other hand, it was found that the college students in this study were less likely to celebrate 
Vietnamese holidays or to plan to pass on Vietnamese customs and values to later generations than the high school students.

As a matter of fact, many of the college students preferred a non-Vietnamese mate whereas the high school students all preferred a Vietnamese mate. These findings are reminiscent of the Clark and Clark doll play findings. Do Vietnamese adolescents come to prefer White culture and desire to become as "white as possible" in order to be perceived as just like the majority society? There are many questions that need to be addressed relative to Vietnamese youth. This study, however, is significant in that it focused on Vietnamese youth and their immigrant status. Specifically, this study showed that Vietnamese youth that have been in the United States for a relatively long period of time are more susceptible to depression and alienation than recent immigrants. Future research will need to expand on this finding. Although a major limitation of this study is subject size, it does mirror the number of Vietnamese that are found in major educational imstitutions in the northeast. Still, future research studies will need to increase the subject size.

\section{NOTES}

'Requests for reprints should be addressed to the first author at Center for the Study of Race \& Ethnicity in America, Box 1886, Brown University, Providence, Rhode Island 02912.

${ }^{2}$ Chao, R. K. (1994). "Beyond Parental Control and Authoritarianism Parenting Style: Understanding Chinese Parenting through the Cultural Notion of Training" Child Development 65, 1111-1119.

[DuBois, W.E.B. (1989) The Souls of Black Folk. New York: Penguin.

${ }^{4}$ Kunz, E.F. (1973) "The Refugee in Flight: Kinetic Models and Form of Displacement." International Migration Review 7, 125-146.

${ }^{5}$ Henkin, A. B., and Nguyen, L. T. (1982) "Vietnamese Refugees in the United States: Adaptation and Transitional Status," The Journal of Ethnic Studies 9, 10-116.

'Jones, W., and Strand, P. (1986) "Adaptation and Adjustment Problems among Indochinese Refugees," Sociology and Social Research 71, 42 46.

${ }^{7}$ Mindel, C. H., Van Tran, T., and Wright, R. (1987) "Alienation among Vietnamese Refugees in the United States: A Causal Approach," Journal of Social Service Research 11, 59-75. 
${ }^{8}$ Mindel et al.

${ }^{9}$ Benjamin, M. E., Benjamin, R., and Tran, T. Van (1983) "Alienation Among Vietnamese Students in the United States," Free Inquiry in Creative Sociology 11, 32-34.

${ }^{10}$ Forward, J., and Rick, K. (1992) "Acculturation and Perceived Intergenerational Differences Among Hmong Youth," Journal of Cross Cultural Psychology 23, 85-94.

${ }^{11 H e n k i n, ~ N . ~ Z ., ~ a n d ~ W e i n s t e i n-S h r, ~ G . ~(1991) ~ " C o n t i n u i t y ~ a n d ~ C h a n g e: ~}$ Intergenerational Relations in Southeast Asian Refugees Families," Marriage and Family Review 16, 351-367; Forward and Rick; Annin, P., Ingrassia, M., King, P., Scigliano, E., and Tizon, A. (1994) "America's new wave of runaways," Newsweek 4, 64-65.

${ }^{12}$ Forward and Rick.

13Jones and Strand; Stein, B. N. (1981) "The Refugee Experience: Defining the Parameters of a Field Study." International Migration Review 15, 320-330; Haines, D., Rutherford, D., and Thomas, P. (1989) Refugees as Immigrants: Cambodians, Laotians, and Vietnamese in American. (Totowa: Rowman \& Littlefield).

${ }^{14}$ Haines et al., 1989.

${ }^{15}$ Matsuoka, J. (1990) "Differential Acculturation Among Vietnamese Refugees," Social Work 35, 341-345.

16Matsuoka.

${ }^{17}$ Nguyen, N. A., and Williams, H. L. (1989) "Transition from East to West: Vietnamese Adolescents and Their Parents," Journal of the American Academy of Ahild Adolescent Psychiatry 28, 505-515.

${ }^{18}$ Nguyen and Williams.

${ }^{19}$ Callies, A., Neider, J., and Westermeyer, J. (1989) "Psychosocial Adjustment of Hmong Refugees during Their First Decade in the United States: A Longitudinal Study," The Journal of Nervous and Mental Disorders 177, 132-139.

${ }^{20}$ Nguyen, N.A., and Peterson, C. (1993) "Depressive Symptoms Among Vietnamese-American College Students," The Journal of Social Psychology 133, 65-71, 
Ethnic Studies Review Volume 20

${ }^{21}$ Nguyen and Peterson.

22Haines et al.

${ }^{23}$ Henkin and Nguyen; Forward and Rick.

${ }^{24}$ Celano, M. P., and Tyler, F. B. (1991) "Behavioral Acculturation Among Vietnamese Refugees in the United States, "The Journal of Social Psychology 131, 373-385.

${ }^{25}$ Celano and Tyler.

${ }^{26}$ Celano and Tyler; Nguyen and Peterson; Nguyen and Williams; Jones and Strand; Haines et al.

${ }^{27}$ Celano and Tyler.

${ }^{28}$ Nguyen and Peterson.

29.Jones and Strand.

${ }^{30}$ Haines et al.

${ }^{31}$ Haines et al.

${ }^{32}$ Haines et al.

${ }^{33}$ Damon, W., and Miller F. (1993) "Roots of Violence in Contemporary Urban Life: Missing Pathways of Social and Self Development," Unpublished manuscript: Brown University.

${ }^{34}$ Miller, F. S. (in press) "Living in Chaos: Social Adaptation Processes of African American Youth," in J. C. S. Fray and J. King (eds.) Psychological and Physiological Dimensions of Black Child Development. (New York: Erlbaum). 
Fayneese Miller is an Associate Professor of Education and Human Development and the Director of the Center for the Study of Race \& Ethnicity in America at Brown University. She has published on social adaptation processes of "minority" adolescents, focusing on such issues as hope, alienation/social integration, and social/political reasoning. She has also published articles on race relations in the United States, including an edited volume for the American Behavioral Scientist entitled "Facing the Future: The Status of Affirmative Action in the 21st Century." Currently, she is at work on a project on cross-racial friendships and race relations among young people. My Do recently completed her $M$. A. degree in applied economics for the University of Hawaii. Previously she received her A. B. degree with honors in American Civilization from Brown University. Her undergraduate and graduate research focused on the effects of immigration on the social development of Vietnamese youth and the impact of internal migration in Vietnam on the rice import. Jason Sperber is a research associate at the Center of the Study of Race \& Ethnicity in America at Brown University. He received his A. B. with honors in Ethnic Studies from Brown University. He currently assists in the planning of the Center's events and programs on issues of race, serves on the Center's liasion with student organizations, and assists with the Ethnic Studies concentration. 
Table 1

Academic Achievement Among Young Vietnamese Youth

\begin{tabular}{lcccc}
\hline & \multicolumn{2}{c}{ College Students } & \multicolumn{2}{c}{ High School Students } \\
\hline Grades & Males & Females & Males & Females \\
\hline As & $55 \%$ & $37 \%$ & $16 \%$ & \\
As \& Bs & $27 \%$ & $42 \%$ & $16 \%$ & $57 \%$ \\
Cs & $18 \%$ & $21 \%$ & $50 \%$ & \\
Ds & & & $16 \%$ & $43 \%$ \\
& & & & \\
Homework: & $17 \%$ & & & \\
<1 hour & $25 \%$ & $17 \%$ & $71 \%$ & $25 \%$ \\
$2-4$ hours & $42 \%$ & $56 \%$ & $29 \%$ & $63 \%$ \\
$4-6$ hours & $17 \%$ & $28 \%$ & & $13 \%$ \\
$>6$ hours & & & & \\
\hline & $\mathrm{N}=12$ & $\mathrm{~N}=19$ & $\mathrm{~N}=7$ & $\mathrm{~N}=8$
\end{tabular}


Table 2

Perceived Parental Involvement In and Attitudes Toward Achievement Behavior

\begin{tabular}{|c|c|c|c|c|}
\hline & \multicolumn{2}{|c|}{ College Students } & \multicolumn{2}{|c|}{ High School Students } \\
\hline & Males & Female & Males & Females \\
\hline Parents Encourage/Help & $25 \%$ & $42 \%$ & $19 \%$ & $20 \%$ \\
\hline $\begin{array}{l}\text { Parents Get Upset } \\
\text { About Bad Grades }\end{array}$ & $75 \%$ & $14 \%$ & $14 \%$ & $25 \%$ \\
\hline Parents Punish Bad Grades & $0 \%$ & $14 \%$ & $29 \%$ & $13 \%$ \\
\hline $\begin{array}{l}\text { Other Types of Reactions } \\
\text { For Bad Grades }\end{array}$ & $25 \%$ & $43 \%$ & $43 \%$ & $25 \%$ \\
\hline $\begin{array}{l}\text { Good Grades/Parents } \\
\text { Encourage to do Better }\end{array}$ & $8 \%$ & $5 \%$ & $29 \%$ & $63 \%$ \\
\hline Good Grades/Parents Happy & $58 \%$ & $79 \%$ & $43 \%$ & $13 \%$ \\
\hline $\begin{array}{l}\text { Parents Think All Grades } \\
\text { Should Be Good }\end{array}$ & $33 \%$ & $16 \%$ & $0 \%$ & $13 \%$ \\
\hline $\begin{array}{l}\text { Good Grades/Parents } \\
\text { Reward }\end{array}$ & $0 \%$ & $0 \%$ & $29 \%$ & $13 \%$ \\
\hline
\end{tabular}

$N=12 \quad N=19 \quad N=7 \quad N=8$


Table 3

Means and Standard Deviations for Depression Scores Among Vietnamese Youth

$\begin{array}{lll}M=15.37 & S D=3.30 & N=19 \\ M=17.33 & S D=3.00 & N=12 \\ M=21.75 & S D=3.30 & N=7 \\ M=22.40 & S D=1.94 & N=8\end{array}$

College Females

College Males

High School Males

High School Females

$M=22.40$

$\mathrm{SD}=1.94$

$\mathrm{N}=8$

The lower the score the greater the depression. 